\title{
Prevention and Management of Late Stage Complications in Parkinson's Disease
}

\author{
A. Jon Stoessl
}

\begin{abstract}
The major complications of therapy in PD are motor, autonomic and psychiatric. Motor complications may be associated with altered striatal bioavailability of levodopa, and may in part respond to changes in timing of drug administration, redistribution of dietary protein and the use of controlled-release preparations. Since long-term complications seem to be associated with higher cumulative doses of levodopa, the early use of adjunctive agents such as deprenyl and/or dopamine agonists is encouraged. Autonomic effects include impaired bladder and bowel function, impotence and postural hypotension. If conservative measures are ineffective, pharmacotherapy with domperidone, fludrocortisone, indomethacin or adrenergic agents may be required. Depression in PD is associated with decreased levels of noradrenaline and 5-HT and responds to tricyclic antidepressants. Drug-induced psychosis reflects stimulation of mesolimbic-cortical dopamine receptors. Alternatives include reduction of medication, the use of atypical neuroleptics (which may act at novel subtypes of the dopamine receptor) and electroconvulsive therapy.
\end{abstract}

RÉSUMÉ: Prévention et traitement des complications de la phase tardive de la maladie de Parkinson. Les complications majeures du traitement de la maladie de Parkinson (MP) sont des complications motrices, neuro-végétatives et psychiatriques. Les complications motrices peuvent être associées à des modifications de la biodisponibilité striatale de la lévodopa et peuvent répondre partiellement à des changements dans l'horaire de la prise de médicaments, à la redistribution des protéines de la diète et à l'utilisation de préparations à libération contrôlée. Comme les complications à long terme semblent être associées à des doses cumulatives supérieures de lévodopa, l'utilisation précoce d'agents d'appoint tels le déprényl et/ou les agonistes de la dopamine est encouragée. Les effets sur le système nerveux autonome incluent l'altération de la fonction vésicale et intestinale, l'impuissance et l'hypotension orthostatique. Si les mesures conservatrices sont inefficaces, la pharmacothérapie avec le dompéridone, la fludrocortisone, l'indométhacine ou des agents adrénergiques peut être nécessaire. La dépression dans la MP est associée à des niveaux abaissés de noradrénaline et 5-HT et répond aux antidépresseurs tricycliques. La psychose induite par la médication reflète la stinulation des récepteurs dopaminergiques mésolimbiques-corticaux. Les solutions de rechange incluent la réduction de la médication, l'utilisation de neuroleptiques atypiques (qui peuvent agir au niveau de sous-types nouveaux de récepteurs dopaminergiques) et la sismothérapie.

Can. J. Neurol. Sci. 1992: 19:113-116

While people in the early stages of Parkinson's disease (PD) respond well to most therapy, as the disease progresses and duration of treatment increases, so unfortunately does the incidence of adverse events. The major complications are motor, autonomic and psychiatric. Adequate preventative and therapeutic strategies assume an understanding of their pathogenesis, which is unfortunately frequently lacking. This article will attempt to briefly review current thinking on the mechanisms for these complications and to outline current practice and future approaches to their management. Because levodopa in combination with a peripheral decarboxylase inhibitor is administered to almost all patients with advanced disease, the paper will assume its use.

\section{Motor Complications}

In terms of frequency, the most important long-term effects are those on the motor system. The initially smooth and pre- dictable response to levodopa is replaced by the emergence of end-of-dose deterioration, progressively shorter duration of benefit, lack of benefit following some (or all) doses. and involuntary movements or dyskinesias. ${ }^{\prime}$ Dyskinesias usually occur at the time of maximum therapeutic benefit (peak dose or "I-D-I" for Immobile-Dyskinetic-Immobile), or may in some patients occur primarily during changes in mobility from "off" to "on" or the reverse (diphasic or "D-I-D" for Dyskinetic-ImprovedDyskinetic). ${ }^{2}$ Careful observation over several days will usually allow one to determine some kind of pattern, but in some patients, there are totally unpredictable and rapid fluctuations ("yo-yoing") from immobility to dyskinesia.

Predictable end-of-dose deterioration and peak dose dyskinesias are both thought to reflect alterations in striatal bioavailability of levodopa. There is a rough but imperfect correlation between plasma levels of levodopa and clinical state. ${ }^{3.4}$ Additional factors include passage of levodopa across the blood-

From the Department of Clinical Neurological Sciences, University of Western Ontario, University Hospital, London

Reprint requests to: A. Jon Stoessl, Department of Clinical Neurological Sciences, University of Western Ontario, University Hospital, 339 Windermere Road, London, Ontario, Canada N6A 5A5 
brain barrier by a process dependent upon a saturable large neutral amino acid transport system, ${ }^{5}$ and the capacity for storage of newly-synthesized dopamine within synaptic vesicles of surviving nigrostriatal neurons. These issues may be of great practical importance in some patients. For example, some individuals may deteriorate after a large meal or find that levodopa taken with meals is ineffective. This is not simply a reflection of delayed gastric emptying or failed transport from the gut into the bloodstream, as demonstrated by deterioration following heavy protein intake in patients receiving continuous intravenous levodopa. ${ }^{6}$ These patients may benefit from taking their levodopa $30 \mathrm{~min}$ prior to or $60 \mathrm{~min}$ after meals, and the implementation of a diet with protein intake restricted during the day and maximized in the evening, or simply taking multiple small meals rather than three heavy ones. ${ }^{7}$

The importance of synaptic vesicular storage in smooth motor performance is more controversial, but is supported by the observation that patients with advanced disease and fluctuations are as sensitive to the therapeutic effects of levodopa as those with less advanced disease and a smooth response, but the duration of benefit is shorter and the threshold for dyskinesias is lower in fluctuators. ${ }^{8.9}$ These observations have not been confirmed by other investigators, however. ${ }^{10.11}$ In those patients with reduced "buffering" capacity due to advanced nigrostriatal degeneration and impaired synaptic vesicular storage, exogenous levodopa is presumably converted to dopamine by nonaminergic neurons. ${ }^{12}$

Ultimately then, one would like to ensure smooth delivery of levodopa to the striatum, avoiding peaks followed by long periods of subtherapeutic levels. One way of achieving this is to simply give lower doses more frequently. Although seemingly rational, this approach is not always effective. Nutt ${ }^{5}$ has argued that there are theoretical drawbacks, in that higher individual doses of levodopa may provide an increased duration of benefit without necessarily exacerbating dyskinesias, while the use of lower doses may simply result in failure to reach a therapeutic threshold. Some patients may therefore improve when returned to larger individual doses of levodopa given less frequently. Controlled-release forms of levodopa have gone through many growing pains. Effective preparations are now available. Although long-term experience is lacking, these drugs seem to be moderately useful for patients with predictable fluctuations and allow one to decrease the frequency of dosing by about $30 \%$, although the total daily levodopa requirement is increased by approximately $25 \% .^{13}$

Controlled-release forms of levodopa confer another theoretical advantage in terms of preventing the development of fluctuations. Experimental evidence indicates that pulsatile administration of levodopa or dopamine agonists results in sensitization of the behavioural response to these treatments. ${ }^{14.15}$ If this sensitization corresponds to the development of dyskinesias in humans, the maintenance of near-steady state levels even in the early stages of the disease may ultimately prevent long-term motor complications.

Deprenyl (selegiline) may be another useful adjunct. In patients with predictable end-of-dose deterioration on levodopa alone, blockade of the oxidative deamination of dopamine by deprenyl may allow one to manage this "wearing off" phenomenon without increasing the total daily dose of levodopa. ${ }^{16}$ Theoretically, there may be an additional advantage in terms of stabilization of striatal dopamine levels and long-term prevention of dyskinesias, as discussed above.

Although there is very little direct evidence of levodopa toxicity, many people have argued that the development of longterm complications is associated with high cumulative intake of this drug. The effects of prolonged duration of therapy are difficult to separate from those of natural disease progression over time, and in this author's view, such considerations do not justify withholding levodopa from a patient who requires symptomatic relief. However, the use of high doses of levodopa should be avoided as much as possible, so when a low dose of $300-500 \mathrm{mg} / \mathrm{day}$ is insufficient, adjunctive therapy should be instituted if not already in place. In patients with end-of-dose deterioration, the simple addition of deprenyl may be sufficient, but the symptomatic effect tends to be short-lived, and this approach is inadequate for patients with more complex fluctuations.

Thus, the early use of dopamine agonists is still a very useful approach, and in patients with more advanced disease, is almost certain to be the single most helpful step. Dopamine agonists offer a number of advantages: (i) direct stimulation of dopamine receptors, bypassing the requirement for enzymatic conversion to the active compound, (ii) a longer duration of action than levodopa, (iii) lack of a saturable system for transport across the blood brain barrier, thereby avoiding the issue of competition with dietary large neutral amino acids and (iv) fewer dyskinesias than are encountered with a dose of levodopa providing equivalent relief from bradykinesia and rigidity. ${ }^{17}$ This last and most critical point may relate to preferential stimulation of D2 receptors, the implications of which are discussed by Bedard in this volume. Finally, new technology will ultimately allow the administration of dopamine agonists by alternate routes such as sublingual, subcutaneous or transcutaneous, and this may also be highly advantageous.

In summary then, how do we mange the difficult fluctuator? The first step is prevention, by avoiding high does of levodopa, using adjunctive therapy if necessary, and by trying to provide steady state delivery of levodopa. This may involve the use of controlled-release preparations, or the addition of deprenyl. In the patient who has already developed fluctuations, a similar approach is used. Steady state delivery of levodopa may now also require the use of a protein redistribution diet (or continuous intravenous or intestinal infusion of levodopa in experimental settings). Although not yet tested in PD patients, COMT inhibitors may also optimize levodopa pharmacokinetics. ${ }^{18}$ If the patient is already on a high dose of levodopa, attempts should be made to reduce the dose and replace it with a dopamine agonist, although this approach is frequently difficult to apply in practice. If more medication is needed, this should generally be given in the form of an agonist.

In patients with rapid and apparently dose-independent "off" periods, one should consider subcutaneous administration of an agonist such as apomorphine. This drug is not available for routine use in Canada, but may, be obtained by special dispensation from the Health Protection Branch. Patients should always be pretreated with domperidone $10-20 \mathrm{mg}$ PO. A test dose of $1 \mathrm{mg}$ should be administered and the patient observed carefully for benefit and adverse effects (particularly emesis and postural hypotension) for at least 1 hour. Benefit is often dramatic, and typically occurs within 5 to 10 minutes. The duration of action 
is short (40-60 $\mathrm{min}$ ), so bolus injections are primarily of benefit to rapidly reverse disabling "off" periods until the patient's other medications take effect. The size of the dose can be increased by $1 \mathrm{mg}$ increments until benefit is obtained. Typically, $2-4 \mathrm{mg}$ are required per "off" period. This can most conveniently be given by a "pen" syringe. If frequent doses are required throughout the day, consideration should be given to continuous infusion, but the logistical difficulties then become considerable. In appropriately selected patients, considerable benefit may be derived from this approach, but dyskinesias are still a problem, and one should not discontinue levodopa. ${ }^{19}$ Apomorphine can also be given sublingually, although absorption of currently available forms is less predictable, and higher doses are required. ${ }^{20}$

\section{Autonomic Complications}

Patients with parkinsonism may suffer from autonomic dysfunction as a direct outcome of the disease itself, as a result of medications, or both. Obviously, prominent autonomic difficulties early in the course of the illness should suggest the possibility of an alternate diagnosis, such as Shy-Drager syndrome, striatonigral degeneration or multi-system atrophy. Constipation is common, particularly with anticholinergics or levodopa, and should be treated with the usual preventative and symptomatic therapies. Domperidone may produce diarrhoea and abdominal cramping. Urinary urgency may occur as a result of the disease process, and some patients suffer from disabling urinary retention on levodopa, which may respond to domperidone. Impotence may be multifactorial. It is worth trying an alpha ${ }_{2}$ adrenergic antagonist such as yohimbine, although this has met with limited success in this author's experience. Subcutaneous apomorphine has been successfully used to treat this problem in non-parkinsonian patients, ${ }^{21}$ and should therefore be of theoretical benefit.

Probably the major limiting autonomic problem is postural hypotension, which appears to be mediated at sites both within and outside of the blood-brain barrier. No steps need be taken if the subject is asymptomatic unless the systolic BP is consistently well below $100 \mathrm{~mm} \mathrm{Hg}$. Simple measures such as the liberal use of salt and caffeine may suffice. Support hose and elevation of the head of the bed should probably be tried, but are disappointing in my experience. Domperidone may be helpful in managing the hypotension induced by dopamine agonists, but benefit is inconsistent, perhaps reflecting medication effect at central dopamine receptors. ${ }^{22}$ If these measures fail, more aggressive pharmacological intervention is required. Fludrocortisone is generally quite effective, but its use requires close monitoring for supine hypertension, congestive heart failure and hypokalemia. The anti-hypotensive (and salt-retaining) effect of fludrocortisone may be potentiated by indomethacin. Alpha ${ }_{2}^{-}$ adrenergic antagonists such as yohimbine or idazoxan may also be helpful. Although non-selective MAO inhibitors are frequently included in lists of drugs useful for treating this problem, they may actually exacerbate postural hypotension and are generally best avoided in patients taking other antiparkinson medications.

\section{Neuropsychiatric Complications}

The final group of complications I would like to address is one of the most challenging - the neuropsychiatric aspects of the disease. Cognitive impairment is common in PD and forms a substantial topic in its own right, so will not be dealt with further here. Depression is also common and may of course partly reflect an understandable response to chronic, sometimes debilitating illness. There is however an association between depression and markers of impaired serotonergic and noradrenergic activity. ${ }^{23.24}$ In practice, this means that tricyclic antidepressants may be very useful. To date, there are insufficient data comparing the use of standard agents such as amitriptyline to more novel and 5-HT-selective drugs such as trazodone or fluoxetine. Caution must be exercised if fluoxetine is to be administered to patients on deprenyl, as adverse effects including mania have been reported on this combination. ${ }^{25}$ Anxiety should be interpreted with caution, as it may reflect akathisia due to inadequate dopamine replacement, or be a manifestation of depression.

Drug-induced psychosis is a major problem in long-term management. Psychosis early in the course of the illness may suggest diffuse Lewy body disease. Virtually all antiparkinson medications may be associated with confusion or hallucinations. For this reason, the use of anticholinergics should be limited to low doses, particularly in those with cognitive impairment. Some dopamine agonists, such as lisuride, may be more prone than others to induce psychosis, and this may in part reflect stimulation of other non-dopamine (e.g. 5-HT) receptors. 1 would like to concentrate on dopamine receptors, however.

There are two major telencephalic dopamine projections, the nigrostriatal, arising from the A9 cell group, and the mesocorti$\mathrm{cal} / \mathrm{mesolimbic}$, arising from the nearby A 10 neurons of the ventral tegmental area and projecting to the nucleus accumbens and limbic/olfactory regions. Stimulation of the nigrostriatal system is thought to correlate with antiparkinson medication effects, while blockade of these receptors with classical neuroleptics induces parkinsonism. In contrast, antipsychotic effects are thought to correlate with effects on the mesolimbic/mesocortical projection, possibly mediated by depolarization blockade of A10 neurons, whereas excessive activity may underly schizophrenia. Thus, the atypical neuroleptic clozapine, which causes selective depolarization of $\mathrm{A} 10$ neurons, but does not affect A9 cells, ${ }^{26}$ is relatively devoid of extrapyramidal effects and may be moderately useful in treating drug-induced psychosis in PD. ${ }^{27}$ Its use is limited by agranulocytosis, which occurs in about $1 \%$ of patients and is usually reversible. Furthermore, the selectivity of clozapine for mesolimbic dopamine projections is relative and higher doses may be associated with intolerable sedation and worsening of parkinsonism. Thioridazine is another atypical neuroleptic with a preferential effect on A10 neurons, but the degree of selectivity is incomplete, and it should therefore be used only with great caution in PD. Remoxipride is a novel agent currently undergoing investigation in this setting.

The role of D1 receptors in toxic psychosis is unclear. The distribution of D1 and D2 receptors within the striatum and nucleus accumbens is similar, but in contrast to D2 receptors, whose cortical distribution is limited, D1 receptors are widespread throughout cerebral cortex and may play a role in cognition. ${ }^{28}$ A number of Dl antagonists are currently undergoing investigation as potential antipsychotic agents. Of interest, clozapine, which is relatively devoid of extrapyramidal effects, is a potent (but non-selective) Dl antagonist. As reviewed by Bedard elsewhere in this volume, low-level stimulation of Dl 
receptors may be necessary to allow full expression of D2 mediated behaviours, and the safety and efficacy of DI antagonists in Parkinson patients with psychosis are not established.

Finally, the recent discovery using molecular genetic techniques of $\mathrm{D} 3^{29}, \mathrm{D} 4^{30}$ and $\mathrm{D} 5^{31}$ receptors is of great interest with respect to this problem. The D3 receptor is localized to limbic regions and whereas typical neuroleptics such as haloperidol are far more potent at the D2 receptor than the D3, atypical agents are nearly equipotent at both sites. The D4 receptor has a high affinity for clozapine. Potentially, if one could develop an antipsychotic agent which selectively blocks D3 or D4 receptors but spares the D2 receptor, it may be devoid of extrapyramidal effects, whereas the converse also holds - i.e. a truly selective D2 agonist (many agents previously considered to be selective for the D2 receptor are in fact active at D3 sites) may relieve parkinsonism without inducing psychosis.

Electroconvulsive therapy (ECT) provides short-term relief from parkinsonism, ${ }^{32}$ presumably by upregulating dopamine receptors. A pilot study suggests that ECT may control druginduced psychosis in Parkinson patients, ${ }^{33}$ thereby permitting continued administration of the offending but necessary agents.

\section{Concluding Remarks}

Suggested approaches to the management of long-term complications have been reviewed. This article has concentrated on treatments which are either already available or whose use is on the horizon, and based on classical views of the disease. Other avenues, such as transplantation or the manipulation of alternate neurotransmitter systems have not been addressed, but may become of great importance, particularly in more advanced disease.

\section{ACKNOWLEDGEMENT}

A.J.S. is supported by a Career Scientist Award from the Ontario Ministry of Health.

\section{REFERENCES}

1. Marsden CD, Parkes JD, Quinn N. Fluctuations of disability in Parkinson's disease: clinical aspects. In: Marsden CD, Fahn S, eds. Movement Disorders. London: Butterworth, 1982: 96-122.

2. Muenter MD, Sharpless NS, Tyce GM, et al. Patterns of dystonia ('I-D-I' and 'D-I-D') in response to L-dopa therapy for Parkinson's disease. Mayo Clin Proc 1977; 52: 163-174.

3. Shoulson I, Glaubiger GA, Chase TN. On-off response. Clinical and biochemical correlations during oral and intravenous levodopa administration in parkinsonian patients. Neurology 1975; 25: $1144-1148$.

4. Mouradian MM, Juncos JL, Fabbrini G, et al. Motor fluctuations in Parkinson's disease: pathogenetic and therapeutic strategies. Ann Neurol 1987; 22: 475-479.

5. Nutt JG. On-off phenomenon: relation to levodopa pharmacokinetics and pharmacodynamics. Ann Neurol 1987; 22: 535-540.

6. Nutt JG, Woodward WR, Hammerstad JP, et al. The "on-off" phenomenon in Parkinson's disease: relation to levodopa absorption and transport. N Engl J Med 1984; 310: 483-488.

7. Pincus JH, Barry K. Protein redistribution diet restores motor function in patients with dopa-resistant "off" periods. Neurology 1988; 38: 481-483.

8. Fabbrini G, Juncos J, Mouradian MM, et al. Levodopa pharmacokinetic mechanisms and motor fluctuations in Parkinson's disease. Ann Neurol 1987; 21:370-376.

9. Mouradian MM, Heuser IJE, Baronti F, et al. Pathogenesis of dyskinesias in Parkinson's disease. Ann Neurol 1989; 25: 523-526.
10. Gancher ST, Nutt JG, Woodward W. Response to brief levodopa infusions in parkinsonian patients with and without motor fluctuations. Neurology 1988; 38: 712-716.

11. Kempster PA, Frankel JP, Bovingdon $\mathrm{M}$, et al. Levodopa peripheral pharmacokinetics and duration of motor response in Parkinson's disease. J Neurol Neurosurg Psychiatry 1989; 52: 718-723.

12. Melamed E, Hefti F, Wurtman RJ. Nonaminergic striatal neurons convert exogenous L-dopa to dopamine in parkinsonism. Ann Neurol 1980; 8: 558-563.

13. Cedarbaum JM, Breck L, Kutt H, et al. Controlled-release levodopa/carbidopa. II. Sinemet CR4 treatment of response fluctuations in Parkinson's disease. Neurology 1987; 37: 1607-1612.

14. Martin-Iverson MT, Stahl SM, Iversen SD. Chronic administration of a selective dopamine D-2 agonist: factors determining behavioural tolerance and sensitization. Psychopharmacology 1988; 95: 534-539.

15. Juncos JL, Engber TM, Raisman R, et al. Continuous and intermittent levodopa differentially affect basal ganglia function. Ann Neurol 1989; 25: 473-478.

16. Lees AJ, Shaw KM, Kohout LJ, et al. Deprenyl in Parkinson's disease. Lancet 1977; 2: 791-795.

17. Rinne UK. Combined bromocriptine-levodopa therapy early in Parkinson's disease. Neurology 1985; 35: 1196-1198.

18. Mannisto PT, Kaakkola S. Rationale for selective COMT inhibitors as adjuncts in the drug treatment of Parkinson's disease. Pharmacol Toxicol 1990; 66: 317-323.

19. Stibe CMH, Lees AJ, Kempster PA, et al. Subcutaneous apomorphine in parkinsonian on-off oscillations. Lancet 1988; 1: 403406.

20. Lees AJ, Montastruc JL, Turjanski N, et al. Sublingual apomorphine and Parkinson's disease. J Neurol Neurosurg Psychiatry 1989; 52: 1140.

21. Lal S, Laryea E, Thavundayil JX, et al. Apomorphine-induced penile tumescence in impotent patients - preliminary results. Prog Neuro-Psychopharm Biol Psychiatry 1987; 11: 235-242.

22. Parkes, JD. Domperidone and Parkinson's disease. Clin Neuropharmacol 1986; 9: 517-532.

23. Mayeux R, Stern Y, Cote L, et al. Altered serotonin metabolism in depressed patients with Parkinson's disease. Neurology 1984; 34: 642-646.

24. Chan-Palay V, Asan E. Alterations in catecholamine neurons of the locus coeruleus in senile dementia of the Alzheimer type and in Parkinson's disease with and without dementia and depression. J Comp Neurol 1989; 287: 373-392.

25. Suchowersky O, deVries J. Possible interactions between deprenyl and Prozac. Can J Neurol Sci 1990; 17: 352-353.

26. Hand TH, Hu X-T, Wang RY. Differential effects of acute clozapine and haloperidol on the activity of ventral tegmental $(A 10)$ and nigrostriatal (A9) dopamine neurons. Brain Res 1987; 415: 257. 269.

27. Friedman $\mathrm{JH}$. The management of the levodopa psychoses. Clin Neuropharmacol 1991; 14: 283-295.

28. Sawaguchi T, Goldman-Rakic PS. DI dopamine receptors in prefrontal cortex: involvement in working memory. Science 1991; 251: $947-950$.

29. Sokoloff P, Giros B, Martres M-P, et al. Molecular cloning and characterization of a novel dopamine receptor (D3) as a target for neuroleptics. Nature 1990; 347: 146-150.

30. Van Tol HHM, Bunzow JR, Guan H-C, et al. Cloning of the gene for a human dopamine D4 receptor with high affinity for the antipsychotic clozapine. Nature 1991; 350: 610-614.

31. Sunahara RK, Guan H-C, O'Dowd BF, et al. Cloning of the gene for a human dopamine D5 receptor with higher affinity for dopamine than D1. Nature 1991; 350: 614-619.

32. Anderson K, Balldin J, Gottfried CG. A double-blind evaluation of electroconvulsive therapy in Parkinson's disease with "on-off" phenomena. Acta Neurol Scand 1987; 76: 191-199.

33. Hurwitz TA, Calne DB, Waterman K. Treatment of dopaminomimetic psychosis in Parkinson's disease with electroconvulsive therapy. Can J Neurol Sci 1988; 15: 32-34. 